\title{
Magnitude of Central Obesity and its Associated Factors Among Adults in Urban Areas of Northwest Ethiopia
}

This article was published in the following Dove Press journal: Diabetes, Metabolic Syndrome and Obesity: Targets and Therapy

\author{
Meseret Derbew Molla $\mathbb{D}^{1}$ \\ Haileab Fekadu Wolde (1D ${ }^{2}$ \\ Asmamaw Atnafu (D) 3,4 \\ 'Department of Biochemistry, School of \\ Medicine, College of Medicine and Health \\ Sciences, University of Gondar, Gondar, \\ Ethiopia; ${ }^{2}$ Department of Epidemiology \\ and Biostatistics, Institute of Public \\ Health, College of Medicine and Health \\ Sciences, University of Gondar, Gondar, \\ Ethiopia; ${ }^{3}$ Department of Health System \\ and Policy, Institute of Public Health, \\ College of Medicine and Health Sciences, \\ University of Gondar, Gondar, Ethiopia; \\ ${ }^{4}$ Dabat Research Centre Health and \\ Demographic Surveillance System, \\ Institute of Public Health College of \\ Medicine and Health Science, University \\ of Gondar, Gondar, Ethiopia
}

\begin{abstract}
Purpose: Obesity is becoming one of the most common public health problems worldwide. In particular, central obesity which indicates abnormal fat accumulation in the abdominal regions is highly associated with the risk of getting cardiometabolic diseases and their progression to end stage diseases or death. However, in developing countries, including Ethiopia less attention has been given to analyze the magnitude and associated factors of it. Therefore, we aimed to determine the prevalence of central obesity and its associated factors among adults in urban areas of Northwest Ethiopia.
\end{abstract}

Methods: A cross-sectional study was conducted among 773 adults who lived in urban areas of Northwest Ethiopia from April 1 to May 30, 2019. Central obesity was assessed using both waist to hip ratio and waist circumference of the participants. Data were analyzed using STATA 14.0. The factors associated with central obesity were identified by binary logistic regression analyses using $95 \%$ confidence interval and the degree of association of the factors was measured using adjusted odds ratio (AOR). $P$-value $<0.05$ was used to declare statistical significance.

Results: The prevalence of central obesity with waist circumference and waist to hip ratio definition criteria was $37.6 \%$ and $35.7 \%$, respectively. According to body mass index, about $26.26 \%$ and $10.29 \%$ of the study participants were overweight and obese, respectively. A one-year increase in age ( $\mathrm{AOR}=1.05 ; 95 \% \mathrm{CI}: 1.03-1.07)$, being female $(\mathrm{AOR}=9.62 ; 95 \% \mathrm{CI}$ : 4.84-19.12) and eating of liquid oils ( $\mathrm{AOR}=2.58 ; 95 \% \mathrm{CI}: 1.71-3.90)$ were found to have statistically significant variables with central obesity.

Conclusion: The prevalence of central obesity was relatively high in comparison with similar studies. Thus, governmental and nongovernmental organizations that work in the health system as well as health professionals should focus on the preventive measure of central obesity to control its associated disorders at an early stage.

Keywords: central obesity, magnitude, associated factor, Northwest Ethiopia

\section{Introduction}

Obesity is a complex disorder that is characterized by excess fat accumulation in the body. ${ }^{1}$ Globally, it is becoming one of the major public health problems. ${ }^{2,3}$ It is estimated that approximately one-third of the world's population are overwieght or obese. ${ }^{4}$ Although the prevalence of obesity varies across the world, it has an extensive impact on the life expectancy of the population. ${ }^{5}$ In the USA, the prevalence of obesity and its associated disorders are steadily increasing in the last two decades. ${ }^{6}$ According to published reports, a high proportion (up to $50 \%$ ) of
Correspondence: Meseret Derbew Molla Department of Biochemistry, School of Medicine, College of Medicine and Health Sciences, University of Gondar, PO Box

196, Gondar, Ethiopia

Tel +251918331617

Email messidrm19@gmail.com 
the African population, especially those who are living in urban areas are under obesity or overweight, and it is expected that by 2025, the majority of obese individuals will be found in low and middle income countries. ${ }^{7,8}$ As Ethiopia is one of these countries, the incidence and prevalence of general obesity is becoming extremely high. ${ }^{9-11}$ The increment of sedentary lifestyle, nutritional transition, bad behavioral practice such as smoking and alcohol drinking, fewer physical activities, and urbanization are believed to be the major contributing factors for the global epidemic of obesity. ${ }^{12-14}$ These factors along with obesity increase the prevalence and incidence rate of noncommunicable diseases both in developing and underdeveloping countries, which results in a double burden, especially in low and middle income countries, including Ethiopia. ${ }^{15,16}$ Therefore, screening for obesity at an early stage is very important to overcome associated comorbidities and death, but addressing the site of excess fat accumulation in the body is believed to be a key determinant factor.

Based on the site of fat storage, obesity can be grouped into peripheral (gynoid), central (android), or a combination of both. The storage of excess fat in the buttocks, hips and thighs refers peripheral obesity. In central obesity, excess fat accumulates in the abdominal area which is a risky region for fat storage since vital organs and their bloodstream are located there. ${ }^{17,18}$ Several reports have confirmed that central obesity is the most common form of obesity that associated with diverse health problems, such as diabetes mellitus, hypertension, cardiovascular diseases and several types of cancer. ${ }^{17,19-21}$ In addition, the economic burden, including unemployment and early retirement from their job due to obesity-related complications is very high. Psychological and quality of life can also be compromised due to the development of obesity associated cardiometabolic problems. ${ }^{22,23}$ Body mass index (BMI) is a common anthropometric measurement to indicate the obesity status or general adiposity of the individuals. However, it does not tell the area of excess fat accumulation and abdominal obesity-associated health problems. $^{24-26}$

Besides, BMI does not differentiate weight gain due to excess fat accumulation or high muscle mass in the body.-

27 Furthermore, central obesity (abdominal fat accumulation) alone can help to determine the risk of getting obesity-related disorders/cardiometabolic risks, but BMI without measuring visceral (abdominal) obesity does not show the exact risk of developing cardiometabolic risks. In some cases, centrally obese individuals may have normal or low BMI values. For instance, in older individuals, their BMI may be normal or low due to the degeneration of their lean muscle mass, but the central obesity can be high because of body fat redistribution. ${ }^{28,29}$ Thus, measurement of central obesity with waist circumference and/or waistto-hip ratio is helpful to identify the risky types of fat storage in the body and its related complications. ${ }^{26,30}$ Besides, central obesity is defined based on the International Diabetic Federation (IDF) and World Health Organization. Accordingly, in this study, central obesity was defined with Europid driven cutoff point, as IDF suggested Sub-Saharan Africans (SSA) use it. However, to the best of our knowledge, empirical evidence on the prevalence of central obesity and its associated factors is scarce. Therefore, we aimed to determine the prevalence and associated factors of central/abdominal obesity among adults in urban areas of Northwest Ethiopia.

\section{Methods and Participants Study Design and Period}

A community based cross-sectional study was conducted from April 1 to May 30, 2019 in urban areas of Northwest Ethiopia.

\section{Participants}

All adults aged $\geq 18$ years living in Gondar town and urban kebeles (the lowest administrative unit of Ethiopia or villages within each woreda (district)) of Dabat Health and Demographic Surveillance Site (HDSSs) Northwest Ethiopia were the source of population, whereas those adults living in Gondar town and urban kebeles of Dabat HDSSs for at least six months were the study population. Besides, all adults aged $\geq 18$ years who lived there for at least six months and were available during the data collection period in Gondar town and urban kebeles of Dabat HDSSs were included, while pregnant and postpartum women, clinically confirmed edematous and abdominal distended adults by health professionals were excluded from the study. A total of 773 study participants were selected using multistage sampling technique. First, two study sites (Gondar town, and Dabat HDSS) were selected. Of these sites, all of the four urban kebeles of Dabat HDSS, and six of the total 23 kebeles of Gondar town with the lottery method were selected. Then, households were chosen through systematic random sampling technique by taking equal proportion of study participants from each of the selected kebeles. Finally, from each household, 
one study participant was selected using the lottery method if more than one eligible individual resided in the house.

The sample size was determined using the formula for the estimation of a single population proportion with an assumption of $95 \%$ confidence interval, $5 \%$ margin of error, design effect of two and $50 \%$ expected proportion of central obesity. To compensate for the nonresponse rate, $10 \%$ of the determined sample size was added and the final sample size was 845 .

\section{Data Collection Procedure}

The data were collected using a pretested, semi-structured interviewer-administered questionnaire which was prepared based on World Health Organization stepwise survey tool for noncommunicable diseases (NCDs). The questionnaire took account of sociodemographic characteristics (age, sex, marital status, religion, educational status, occupation, and wealth index) and behavioral risks of NCDs, such as physical activity, dietary habit, smoking status, and alcohol consumption. WHO-identified risk factors of NCDs were expanded and optimized to suit local needs of the study areas. The questionnaire was first developed in English language then translated into local Amharic language for appropriateness and ease of approaching the study participants, and then re-translated back into English to check its consistency. The dietary and behavioral habits of the participants were assessed using a dichotomous yes and no questionnaire with expanded questions for those who answered yes about the type, duration and frequency of dietary, alcohol drinking and cigarette smoking habits. Then, alcohol drinking was defined as intake of any type of alcohol such as beer, wine, or locally prepared alcoholic beverages more than once per week for the last one year irrespective of the amount, and those who drink less than once per week for the last one year or never drink alcoholic products were taken as nondrinkers. Besides, smokers were defined as having a cigarette smoking practice within the last one year regardless of the amount, and those who never smoked in their lifetime or smokers prior to one year were taken as non-smokers. The physical activity of the respondents was categorized as vigorous, moderate, and poor physical activities based on the WHO and international physical activities analysis guidelines. A vigorousintensity activity was defined as any activity that causes a large increase in breathing or heart rate (eg, running, carrying, or lifting heavy loads, digging or construction work) that continued for at least 30 minfor a minimum of three days per week. Moderate-intensity activity was defined as any activity that causes a small increase in breathing or heart rate (brisk walking or carrying light loads) that continued for at least $30 \mathrm{~min}$ for at least three days per week or five or more days of these activities for at least 20 min per day or $\geq 3$ days of vigorous-intensity activity per week of at least 20 min per day. Low-level (sedentary) physical activity was defined as an individual having physical activity that is not meeting any of the abovementioned criteria. ${ }^{31}$ The data was collected by trained public health officers and nurses under the supervision of the principal investigators.

\section{Anthropometric Measurements}

Anthropometric measurements, such as weight, height, waist circumference and hip circumference were measured using standardized methods and adjusted equipment by professional health workers. Weight was measured in kilograms in bare feet without heavy outdoor clothing; height was measured in centimeters using a height board without shoes in an upright position. Consequently, BMI was calculated by dividing weight in $\mathrm{kg}$ with height in square meters, $\mathrm{kg} / \mathrm{m}^{2}$. Then, underweight, normal weight, overweight, and obesity were defined as a BMI $\leq 18.5 \mathrm{~kg} / \mathrm{m}^{2}$, between 18.5 and $24.9 \mathrm{~kg} / \mathrm{m}^{2}$, between 24.9 and $30 \mathrm{~kg} / \mathrm{m}^{2}$ and $\geq 30 \mathrm{~kg} / \mathrm{m}^{2}$, respectively. ${ }^{32}$ Waist circumference (WC) was measured in centimeters at the narrowest mid-point between the lower margin of the lowest palpable rib and the top of iliac crest with flexible plastic tape without heavy outdoor closing. Hip circumference was measured at the greatest posterior protuberance of the buttocks with a flexible plastic tape without heavy outdoor closing. Then, central obesity was determined by using both WHO and IDF definition criteria. Accordingly, central obesity is defined as waist to hip ratio of $>0.90$ for males and $>0.85$ for females or waist circumference $>94 \mathrm{~cm}$ for males and $>80 \mathrm{~cm}$ for females. ${ }^{33}$

\section{Data Quality Assurance}

At each phase of the study, data quality control was performed. Initially, before two weeks of running the actual data, the questionnaire pretest was done on 39 volunteer participants at another urban area of Northwest Ethiopia having the same sociodemographic characteristics. Then, corrections and modifications were made accordingly. A one-day training was given for data collectors before running data collection. The training session covered the entire activities of the study, including objectives and 
methodologies. Data collection was also under close supervision of the primary investigator and supervisors.

\section{Data Processing and Analysis}

The data was entered, coded and cleaned using EpiInfo version 7, then exported to STATA version 14 for analysis. Consequently, descriptive statistics was done using mean, standard deviation, frequency and percentage. To identify factors associated with central obesity, both bivariable and multivariable binary logistic regression analysis were done. The variables in bivariable analysis with $p$-values $\leq 0.2$ were fitted in the multivariable analysis. Then, the strength of association of variables with central obesity was determined by adjusted odds ratio (AOR) with a $95 \% \mathrm{CI}$. A $p$-value of $<0.05$ was considered statistically significant in the multivariable model. Goodness of fitn of the model was checked by the Hosmer-Lemeshow test. Finally, the results were interpreted and presented with tabulation and narration.

\section{Results}

\section{General Characteristics of the Study Participants}

Of the total 845 study participants, the data was collected from 773 study participants which gives a response rate of $91.5 \%$. Of these, the majority, 477 (61.71\%) were females and the mean age of the participants was $37.6 \pm 15.4$. Four hundred and eighty of the participants were married and the majority, 688 (89.12\%) were Orthodox Christian. More than one third, 271 (35.06\%) of the participants were educated up to college and above while most of the study participants, 334 (43.21\%) were unemployed. Out of the total participants, only $15(1.94 \%)$ of them were current cigarette smokers, and about 429 (55.57\%) of the participants ever drank alcohol in their lifetime; of these, 392 (50.71\%) drank alcohol in the last one year more than once per week. Regarding eating of fruit and vegetable diet, $43(5.56 \%)$ and $76(9.83 \%)$ of the participants had history of 5-7 times fruit and vegetable diet intake per week, respectively. Concerning the physical activity status of the participants, more than half of the participants, 404 (52.26\%) practiced poor physical activity. Based on BMI, about $125(26.26 \%)$ and $49(10.29 \%)$ of the participants were overweight and obese, respectively (Table 1).

\section{Prevalence of Central Obesity}

Based on waist to hip ratio and waist circumference definition criteria, the prevalence of central obesity was $35.7 \%$
Table I General Characteristics of the Study Participants Among Adults in Urban Areas of Northwest Ethiopia, 2020 ( $n=773)$

\begin{tabular}{|c|c|c|}
\hline Characteristics & Number & Percent \\
\hline \multicolumn{3}{|l|}{ Age (years) } \\
\hline Mean \pm SD & $37.6 \pm 15.4$ & \\
\hline \multicolumn{3}{|l|}{ Sex } \\
\hline Male & 296 & 38.29 \\
\hline Female & 477 & 61.71 \\
\hline \multicolumn{3}{|l|}{ Marital status } \\
\hline Married & 480 & 62.26 \\
\hline Divorced & 43 & 5.58 \\
\hline Widowed & 42 & 5.45 \\
\hline Never married & 206 & 26.72 \\
\hline \multicolumn{3}{|l|}{ Religion } \\
\hline Orthodox & 688 & 89.12 \\
\hline Muslim & 80 & 10.36 \\
\hline Others & 4 & 0.52 \\
\hline \multicolumn{3}{|l|}{ Educational status } \\
\hline Uneducated & 173 & 22.38 \\
\hline Up to primary school & 119 & 15.39 \\
\hline Secondary school completed & 210 & 27.17 \\
\hline College and above & 271 & 35.06 \\
\hline \multicolumn{3}{|l|}{ Occupation } \\
\hline Governmental & 227 & 29.37 \\
\hline Private job & 176 & 22.77 \\
\hline Unemployed & 334 & 43.21 \\
\hline Retired & 36 & 4.66 \\
\hline \multicolumn{3}{|l|}{ Wealth index } \\
\hline Poor & 309 & 39.97 \\
\hline Medium & 156 & 20.18 \\
\hline Rich & 308 & 39.84 \\
\hline \multicolumn{3}{|l|}{ Current smoking status } \\
\hline Yes & 15 & 1.94 \\
\hline No & 758 & 98.06 \\
\hline \multicolumn{3}{|l|}{ Alcohol drinking status } \\
\hline Yes & 392 & 50.71 \\
\hline No & 381 & 49.29 \\
\hline \multicolumn{3}{|l|}{ Physical activity status } \\
\hline Vigorous & 25 & 3.23 \\
\hline Moderate & 344 & 44.50 \\
\hline Poor & 404 & 52.26 \\
\hline \multicolumn{3}{|l|}{ Type of dietary oil } \\
\hline Solid & 538 & 69.60 \\
\hline Liquid & 235 & 30.40 \\
\hline \multicolumn{3}{|l|}{ Frequency of eating fruit per week } \\
\hline None & 438 & 56.66 \\
\hline I-4 times & 292 & 37.77 \\
\hline 5-7 times & 43 & 5.56 \\
\hline
\end{tabular}

(Continued) 
Table I (Continued).

\begin{tabular}{|l|l|l|}
\hline Characteristics & Number & Percent \\
\hline Frequency of eating vegetables per week & & \\
None & 242 & 31.31 \\
I-4 times & 455 & 58.86 \\
$5-7$ times & 76 & 9.83 \\
\hline Number of days per week eating fat- & & \\
containing foods & & \\
None & 579 & 74.90 \\
I-3 days & 129 & 16.69 \\
4-7 days & 65 & 8.41 \\
\hline BMI & & \\
Underweight & 31 & 6.51 \\
Normal & 271 & 56.93 \\
Overweight & 125 & 26.26 \\
Obese & 49 & 10.29 \\
\hline
\end{tabular}

Abbreviation: BMI; body mass index.

(95\%CI: $32.4-39.2)$ and $37.6 \%$ (95\%CI: $34.3-41.1$, respectively. This condition was more prevalent in females with 86.6 (95\%CI: $82.0-90.4)$ by waist to hip ratio and $85.9 \%$ (95\%CI: $81.4-89.7)$ by waist circumferencee definition criteria (Table 2).

\section{Factors Associated with Central Obesity}

The crude association of independent variables with outcome was done. Accordingly, age, sex, educational status, wealth index, type of oil eating and eating of vegetables and fruits were significantly associated factors with central obesity at $p \leq 0.2$. Of these variables, age, sex and type of oil eating were found to be statistically significant in multivariate analysis at $p<0.05$. The odds of central obesity was increased by $5 \%$ for a unit increase of age in a year $(\mathrm{AOR}=1.05 ; 95 \% \mathrm{CI}: 1.03-1.07)$. The odds of being centrally obese was 9.62 times higher among female study participants compared to their counterparts $(\mathrm{AOR}=9.62$;

Table 2 Prevalence of Central Obesity Based on WHO and IDF Criteria Among Adult Study Participants in Urban Areas of Northwest Ethiopia, $2020(n=773)$

\begin{tabular}{|c|c|c|c|c|}
\hline \multirow[t]{2}{*}{$\begin{array}{l}\text { Central } \\
\text { Obesity }\end{array}$} & \multicolumn{2}{|c|}{$\begin{array}{l}\text { Waist to Hip Ratio } \\
\text { Criteria }\end{array}$} & \multicolumn{2}{|c|}{$\begin{array}{l}\text { Waist Circumference } \\
\text { Criteria }\end{array}$} \\
\hline & Number & $\begin{array}{l}\text { Prevalence } \\
(95 \% \mathrm{Cl})\end{array}$ & Number & $\begin{array}{l}\text { Prevalence } \\
(95 \% \mathrm{Cl})\end{array}$ \\
\hline Total & 276 & $35.7(32.3-39.2)$ & 291 & $37.6(34.2-4 \mid .1)$ \\
\hline Male & 37 & $13.4(9.6-18.0)$ & 41 & $14.1(10.3-18.6)$ \\
\hline Female & 239 & $86.6(82.0-90.4)$ & 250 & $85.9 \%(81.4-89.7)$ \\
\hline
\end{tabular}

95\%CI: 4.84-19.12). The odds of having central obesity was 2.58 times higher in those participants eating liquid oil than those participants who are eating solid oils $(\mathrm{AOR}=2.58 ; 95 \% \mathrm{CI}: 1.71-3.90)($ Table 3$)$.

\section{Discussion}

The recentincrease in obesity is becoming a major public health problem globally. Previously, it was known as a disease of the rich, but now it is increasing alarmingly in developing countries, including Ethiopia. It is in turn associated with the development of obesity-related diseases, which are too difficult to treat, especially in low and middle income countries. Therefore, early identification and screening of obesity, particularly the hidden type of obesity (central obesity) and its associated factors is believed to be effective to overcome the problem. In the current study, central obesity was found to be about $37.6 \%$ by waist circumference and $35.7 \%$ by waist to hip ratio definition criteria. A one-year increase in age $(\mathrm{AOR}=1.05$; 95\%CI: 1.03-1.07), being female (AOR=9.62; 95\%CI: $4.84-19.12)$ and eating of liquid oils ( $\mathrm{AOR}=2.58 ; 95 \%$ CI: $1.71-3.90)$ were found to be statistically significant variables with central obesity.

In this study, the prevalence of central obesity was $37.6 \%$ and $35.7 \%$ with waist circumference and waist to hip ratio definition criteria, respectively. This finding is in line with studies done in $\mathrm{Brazil}^{34}$ and China. ${ }^{35}$ However, our finding is lower than that of studies done in the USA, ${ }^{36}$ Omani adults, ${ }^{37}$ Eastern Sudan, ${ }^{38}$ and Gondar, Ethiopia. ${ }^{39}$ Conversely, the current finding is higher than that of the studies done in Northwest China,${ }^{40}$ Northern Iran, ${ }^{41}$ India, ${ }^{42}$ and Egypt. ${ }^{43}$ These discrepancies may be due to the sociodemographic and ethnic background difference of the study participants. ${ }^{2,44}$ In addition, the residence of the participants might also be one possible reason for the discrepancy in the study findings. For instance, individuals who lived in urban areas and developed countries are at higher risk of getting central obesity due to their overconsumption of processed and energy-dense foods more frequently than that of the rural residents. ${ }^{2,45}$ As an individual consumes a high energy containing diet, the metabolic pathway shifts into anabolic process, including fat biosynthesis, and in turn leads to increment of fats in the circulatory system and the need to store it in order to maintain the metabolic activities. ${ }^{46,47}$ Then, the excess fat will be accumulated in adipose tissue with unlimited fashion and will result in those individuals 
Table 3 Bivariate and Multivariable Logistic Regression Predicting the Odds of Central Obesity Among Adult Study Participants in Urban Areas of Northwest Ethiopia, $2020(n=773)$

\begin{tabular}{|c|c|c|c|c|}
\hline \multirow[t]{2}{*}{ Characteristics } & \multicolumn{4}{|c|}{ IDF Criteria } \\
\hline & Yes & No & COR $(95 \% \mathrm{Cl})$ & AOR $(95 \% \mathrm{Cl})$ \\
\hline Age (years) & & & $1.03(1.02-1.04)$ & $1.05(1.038-1.068)^{*}$ \\
\hline \multicolumn{5}{|l|}{ Sex } \\
\hline Male & 41 & 255 & 1 & $9.6 \mathrm{I}(6.07-15.22)^{*}$ \\
\hline Female & 250 & 227 & $6.85(4.7 I-9.97)$ & \\
\hline \multicolumn{5}{|l|}{ Educational status } \\
\hline Uneducated & 88 & 85 & $1.85(1.26-2.74)$ & $0.73(0.42-1.27)$ \\
\hline Up to primary school & 37 & 82 & $0.81(0.5 I-1.28)$ & $0.71(0.40-1.25)$ \\
\hline Secondary school completed & 6997 & $|4| 174$ & $0.88(0.60-1.28)$ & $0.92(0.58-1.46)$ \\
\hline College and above & & & I & \\
\hline \multicolumn{5}{|l|}{ Occupation } \\
\hline Unemployed & 130 & 204 & I & \\
\hline Governmental & 77 & 150 & $0.80(0.57-1.15)$ & \\
\hline Private job & 68 & 108 & $0.99(0.68-1.44)$ & \\
\hline Retired & 16 & 20 & $\mathrm{I} .25(0.63-2.5 \mathrm{I})$ & \\
\hline \multicolumn{5}{|l|}{ Wealth index } \\
\hline Poor & 7670,145 & 23386,163 & I & $1.17(0.69-1.97)$ \\
\hline Medium & & & $2.50(1.66-3.75)$ & $1.23(0.76-1.98)$ \\
\hline Rich & & & $2.73(1.94-3.84)$ & \\
\hline \multicolumn{5}{|l|}{ Type of dietary oil } \\
\hline Solid & 155 & 383 & 1 & $2.58(1.7 I-3.90)^{*}$ \\
\hline Liquid & 136 & 99 & $3.39(2.47-4.67)$ & \\
\hline \multicolumn{5}{|l|}{ Alcohol drinking status } \\
\hline No & 146 & 235 & I & \\
\hline Yes & 145 & 247 & $0.94(0.7 I-1.26)$ & \\
\hline \multicolumn{5}{|l|}{ Physical activity status } \\
\hline Vigorous & 7129 & 18 & I & \\
\hline Moderate & 155 & 215 & $1.54(0.63-3.79)$ & \\
\hline Poor & & 249 & $1.60(0.65-3.92)$ & \\
\hline \multicolumn{5}{|l|}{ Frequency of eating fruit per week } \\
\hline None & 129 & 309 & $0.22(0.12-0.43)$ & $0.72(0.35-1.52)$ \\
\hline $1-4$ times & 134 & 158 & $0.45(0.23-0.89)$ & $0.85(0.44-1.65)$ \\
\hline $5-7$ times & 28 & 15 & I & \\
\hline \multicolumn{5}{|l|}{ Frequency of eating vegetables per week } \\
\hline None & 67 & 175 & $0.31(0.18-0.53)$ & $00.52(0.27-1.00)$ \\
\hline $1-4$ times & 182 & 273 & $0.54(0.33-0.88)$ & $0.64(0.38-1.08)$ \\
\hline $5-7$ times & 42 & 34 & I & \\
\hline
\end{tabular}

Notes: *Statistically highly significant ( $p$-value $<0.0 \mathrm{I})$; I indicates reference group of the category variables.

Abbreviations: COR, crude odds ratio; AOR, adjusted odds ratio.

becoming centrally obese. ${ }^{47}$ Furthermore, institutionalbased studies may also contribute to higher prevalence of central obesity than that of community-based crosssectional studies even within similar study settings. Thus, the previous study done in Gondar, which is a similar study area with the present study, had found higher prevalence of central obesity than the present study because the study done by Janakiraman et al was focused only among University of Gondar Staff Members. $^{39}$ 
Moreover, the cutoff point difference of waist circumference used in the studies might be another possible justification for the discrepancies. This is because of the cutoff points to determine central obesity across different ethnicities are slightly different due to the composition and shape of body difference between diverse ethnicities. ${ }^{44}$ Scholars reported that the IDF central obesity definition criteria is the best cutoff points for SSA and Asian populations to show the higher threat of cardiometabolic risks. ${ }^{44,48,49}$ Besides, the Adult Treatment Panel (ATP) III of the National Cholesterol Education Program definition criteria of central obesity, which takes a cutoff point of waist circumference $\geq 102 \mathrm{~cm}$ for men and $\geq 88 \mathrm{~cm}$ for women can be used for other ethnic background individuals. ${ }^{50,51}$

This study found that an increase in age was statistically associated with central obesity. This is supported by the studies done in Brazil, ${ }^{34}$ Northwest China, ${ }^{40}$ and Northern Iran ${ }^{41}$ which reported that participants with older age are associated with central obesity. Furthermore, other studies have been reported that being young is a statistically protective factor for the development of central obesity. ${ }^{42}$ This might be due to the fact that the metabolic activity of the body gradually declines as we get older. Lower metabolic activity leads to more storage of fat in the body even with low intake of diet. In addition, as the people get older, the distribution and accumulation of fat shifts into the abdominal region and will have a chance to develop central obesity. ${ }^{52}$

In this study, being female was found to be associated with central obesity. This finding is consistent with the studies done in Brazil,${ }^{34}$ Oman, ${ }^{37}$ Eastern Sudan, ${ }^{38}$ Northern Iran, ${ }^{41}$ and Southern China. ${ }^{53}$ The exact molecular link between being female and central obesity is not clearly addressed yet. However, in this study the association of being female with central obesity may be due to their sedentary lifestyle and practice of less physical activity since most females who live in developing countries, including Ethiopia are housewives. Thus, they may spend more time at home with poor physical activities. ${ }^{54,55}$ In addition, females may have poor awareness of central obesity since most females who are housewives are illiterate and unable to read leaflets posted in public areas and this may be a possible reason for the strong association of female sex with central obesity. ${ }^{56}$ Furthermore, females naturally have a higher body fat percentage than males, which may contribute to having a higher body mass index of these respondents. ${ }^{57}$ And it has been confirmed that the more generally obese individuals may increase the chance of developing central obesity. ${ }^{36}$ This is supported by other studies done in Southern China, ${ }^{53}$ South Africa, ${ }^{58}$ and Chile $^{59}$ which reported that being overweight and obese have a strong positive correlation with central obesity. Although BMI may not accurately differentiate weight gain due to high muscle mass or high fat accumulation in the body, the chance of getting central obesity is high in overweight and obese individuals compared with that of normal weight individuals. ${ }^{27}$ However, we are not saying that centrally obese individuals may not have normal weight since individuals, especially elderly and young people, with normal weight might have central obesity. ${ }^{28,29,60}$ As discussed earlier, central obesity is more dangerous than general or peripheral obesity for health. Therefore, screening of central obesity in the community should be focused in all individuals regardless of the BMI level.

The odds of having central obesity were 2.58 times higher among participants who ate liquid oils than those participants consuming solid oils. The ingestion of dietary types of oil in the development of obesity is still controversial. Many studies done in Africa and South Pacific populations revealed that there is no significant association between having dietary solid oil (coconut oil and palm oil) and the development of obesity. ${ }^{61-63}$ Some other studies revealed that dietary solid oils are less likely to contribute to the development of obesity due to the high content of medium chain fatty acids, because these lipids are certainly oxidized and do not generally accumulate in the adipose tissue ${ }^{64}$ However, the dose of oil consumption matters in the development of obesity; as overeating of solid oil, especially those oils containing long and very long chain fatty acid promotes the initiation and progression of central obesity, while overeating of oils having polyunsaturated fatty acids rather protects the development of obesity, but polyunsaturated containing oils are too expensive and are not usually utilized as common dietary oils in developing countries, including Ethiopia. ${ }^{65,66}$ Polyunsaturated fatty acids (linoleic and linolenic acids) are essential fatty acids by which we are totally dependent on the dietary sources. These fatty acids have antioxidant activity, and may in turn protect the initiation and progression of inflammation, which is believed to be a major risk factor for the development of central obesity. ${ }^{67}$ Therefore, a strong association of liquid oil with central obesity in our study may be due to the type of unsaturated fatty acids found in the oil since most liquid oils found in developing countries may be made up of a 
higher proportion of monounsaturated fatty acids. Thus, surplus monounsaturated fatty acids will be stored in the adipose tissue and will increase the waist circumference of the individuals. ${ }^{68}$ Besides, a strong association of liquid oil with central obesity in our study may also be due to the fear of the participants of solid oils by which they assumed that liquid oils are protective against the development and progression of obesity. So that they may not be worried about the dose of liquid oils, whereas the individuals may believe that overeating of solid oil can contribute to the development of central obesity and may in turn critically restrict the amount of solid oil intake. ${ }^{65}$

\section{Strength and Limitation of the Study}

This study detected the hidden type of obesity in the general population which did not get enough attention in Ethiopia and was the main strength of the study. The limitation of the study were cross-section based study design, and inability of measuring the dietary intakes of total energy and other nutrients.

\section{Conclusion}

More than one-third of the study participants were found to be centrally obese, which is relatively high compared to respective studies. Increasing age, being female and eating of liquid oil were statistically associated with central obesity. Therefore, strategies should be designed to prevent the occurrence of central obesity in accordance with the risk groups. Besides, it is better to conduct communitybased study with a large number of participants in Ethiopia to address the generalized magnitude of central obesity and its factors in the country.

\section{Data Sharing Statement}

Data will be available from the corresponding author upon request.

\section{Ethics Approval and Consent to Participate}

The study was conducted in accordance with the ethical principles of the Declaration of Helsinki. The ethical approved was obtained from the Ethical Review Committee of the College of Medicine and Health Sciences, University of Gondar with ethical approval number $\mathrm{O} / \mathrm{V} / \mathrm{P} / \mathrm{RCS} / 05 / 361 / 2018$. Written informed consent was taken from each study participant before running the study. Confidentiality was kept.

\section{Acknowledgments}

The authors would like to acknowledge the study participants, data collectors and supervisors and University of Gondar.

\section{Author Contributions}

All authors made substantial contributions to conception and design, acquisition of data, or analysis and interpretation of data; took part in drafting the article or revising it critically for important intellectual content; agreed to submit to the current journal; gave final approval of the version to be published; and agree to be accountable for all aspects of the work.

\section{Funding}

No funding was received for this work.

\section{Disclosure}

The authors report no conflicts of interest in this work.

\section{References}

1. National Institutes of Health; National Heart, Lung, and Blood Institute; North American Association for the Study of ObesityThe Practical Guide: Identification, Evaluation, and Treatment of Overweight and Obesity in Adults. National Institutes of Health; National Heart, Lung, and Blood Institute; North American Association for the Study of Obesity; 2000.

2. Blüher M. Obesity: global epidemiology and pathogenesis. Nat Rev Endocrinol. 2019;15:288-298.

3. Bellew W, Bauman A, Kite J, et al. Obesity prevention in children and young people: what policy actions are needed. Public Health Res Pract. 2019;29:e2911902. doi:10.17061/phrp2911902

4. Study GBoD. Global Burden of Disease Study 2015 (GBD 2015) Obesity and Overweight Prevalence 1980-2015. United States: Institute for Health Metrics and Evaluation (IHME) Seattle; 2017.

5. St-Onge M-P, Heymsfield SB. Overweight and obesity status are linked to lower life expectancy. Nutr Rev. 2003;61(9):313-316. doi:10.1301/nr.2003.sept.313-316

6. Wang Y, Beydoun MA, Min J, Xue H. Kaminsky LA and Cheskin LJ. Has the prevalence of overweight, obesity and central obesity levelled off in the United States? Trends, patterns, disparities, and future projections for the obesity epidemic. Int J Epidemiol. 2020.

7. Kamadjeu RM, Edwards R, Atanga JS, Kiawi EC, Unwin N, Mbanya J-C. Anthropometry measures and prevalence of obesity in the urban adult population of Cameroon: an update from the Cameroon Burden of Diabetes Baseline Survey. BMC Public Health. 2006;6:228.

8. Biadgilign S, Mgutshini T, Haile D, Gebremichael B. Moges Y and Tilahun K. Epidemiology of obesity and overweight in sub-Saharan Africa: a protocol for a systematic review and meta-analysis. BMJ Open. 2017;7:e017666.

9. Teshome T. Singh P and Moges D. Prevalence and associated factors of overweight and obesity among high school adolescents in urban communities of Hawassa, Southern Ethiopia. Current Res Nutrition Food Sci J. 2013;1:23-36. 
10. Tebekaw Y, Teller C, Colón-Ramos U. The burden of underweight and overweight among women in Addis Ababa, Ethiopia. BMC Public Health. 2014;14(1):1126. doi:10.1186/1471-2458-14-1126

11. Gebrie A, Alebel A, Zegeye A, Tesfaye B, Ferede A. Tesfaye B and Ferede A. Prevalence and associated factors of overweight/obesity among children and adolescents in Ethiopia: a systematic review and meta-analysis. BMC Obesity. 2018;5(1):19. doi:10.1186/s40608-0180198-0

12. World Health Organization. Obesity: preventing and managing the global epidemic. World Health Organization. 2000.

13. Jensen MD, Ryan DH, Apovian CM, et al. 2013 AHA/ACC/TOS guideline for the management of overweight and obesity in adults: a report of the American College of Cardiology/American Heart Association Task Force on Practice Guidelines and The Obesity Society. J Am Coll Cardiol. 2014;63(25):2985-3023. doi:10.1016/j. jacc.2013.11.004

14. Popkin BM. The nutrition transition in low-income countries: an emerging crisis. Nutr Rev. 1994;52(9):285-298. doi:10.1111/j.17534887.1994.tb01460.x

15. Belachew T. Are we ready for the rising silent epidemic of metabolic syndrome and chronic non-communicable disease in Ethiopia? Ethiop J Health Sci. 2015;25:1-2.

16. Palo SK, Swain S, Priyadarshini S, Behera B, Pati S. Behera B and Pati S. Epidemiology of obesity and its related morbidities among rural population attending a primary health centre of Odisha, India. $J$ Family Med Primary Care. 2019;8(1):203. doi:10.4103/jfmpc. jfmpc_255_18

17. Lee K, Song Y-M, Sung J. Song YM and Sung J. Which obesity indicators are better predictors of metabolic risk?: healthy twin study. Obesity. 2008;16(4):834-840. doi:10.1038/oby.2007.109

18. von Haehling S. Doehner W and Anker SD. Obesity and the heart: a weighty issue. J Am Coll Cardiol. 2006;1:1245.

19. Mooney SJ, Baecker A, Rundle AG. Baecker A and Rundle AG. Comparison of anthropometric and body composition measures as predictors of components of the metabolic syndrome in a clinical setting. Obes Res Clin Pract. 2013;7(1):e55-e66. doi:10.1016/j. orcp.2012.10.004

20. Lee M-J, Wu Y, Fried SK. Wu Y and Fried SK. Adipose tissue heterogeneity: implication of depot differences in adipose tissue for obesity complications. Mol Aspects Med. 2013;34(1):1-11. doi:10.10 16/j.mam.2012.10.001

21. Feldstein CA, Akopian M, Olivieri AO, Kramer AP, Nasi M, Garrido D. Nasi $M$ and Garrido D. A comparison of body mass index and waist-to-hip ratio as indicators of hypertension risk in an urban Argentine population: a hospital-based study. Nutrition Metab Cardiovasc Dis. 2005;15(4):310-315. doi:10.1016/j.numecd.2005.03. 001

22. Cho I-J, Chang H-J, Sung JM, Yun YM. Kim HC and Chung N. Associations of changes in body mass index with all-cause and cardiovascular mortality in healthy middle-aged adults. PLoS One. 2017;12(12):e0189180. doi:10.1371/journal.pone.0189180

23. Müller M, Geisler C. Defining obesity as a disease. Eur J Clin Nutr. 2017;71(11):1256-1258. doi:10.1038/ejen.2017.155

24. Bennasar-Veny M, Lopez-Gonzalez AA, Tauler P, et al. Body adiposity index and cardiovascular health risk factors in Caucasians: a comparison with the body mass index and others. PLoS One. 2013;8 (5):e63999. doi:10.1371/journal.pone.0063999

25. Torun E, Cakir E, Ozguc F, Ozgen IT. Özgüç F and Özgen İT. The effect of obesity degree on childhood pulmonary function tests. Balkan Medical J. 2014;31(3):235. doi:10.5152/balkanmedj.2014.13101

26. Czernichow S, Kengne AP, Stamatakis E. Hamer M and Batty GD. Body mass index, waist circumference and waist-hip ratio: which is the better discriminator of cardiovascular disease mortality risk? Evidence from an individual-participant meta-analysis of 82864 participants from nine cohort studies. Obesity Reviews. 2011; 12:680-687.
27. Park J, Lee ES, Lee DY, et al. Waist circumference as a marker of obesity is more predictive of coronary artery calcification than body mass index in apparently healthy Korean adults: the Kangbuk Samsung Health Study. Endocrinol Metab. 2016;31(4):559-566. doi:10.3803/EnM.2016.31.4.559

28. Wu C-H, Heshka S, Wang J, et al. Truncal fat in relation to total body fat: influences of age, sex, ethnicity and fatness. Int $J$ Obes. 2007;31:1384-1391.

29. Panoulas V, Ahmad N, Fazal A, et al. The inter-operator variability in measuring waist circumference and its potential impact on the diagnosis of the metabolic syndrome. Postgrad Med J. 2008;84 (993):344-347. doi:10.1136/pgmj.2008.068825

30. Schneider HJ, Klotsche J, Silber S, Stalla GK, Wittchen H-U. Measuring abdominal obesity: effects of height on distribution of cardiometabolic risk factors risk using waist circumference and waist-to-height ratio. Diabetes Care. 2011;34(1):e7-e. doi:10.2337/ dc10-1794

31. World Health Organization. Global Physical Activity Questionnaire (GPAQ) Analysis Guide. 2014:2014

32. World Health OrganizationDefining the problem of overweight and obesity. In: World Health Organization Obesity: preventing and managing the global epidemic: Report of a WHO Consultation. Geneva: WHO; 2000:241-243.

33. International Diabetic FederationThe IDF consensus worldwide definition of the metabolic syndrome. IDF Communications. 2006;1-24.

34. de Marins VR, Almeida RV, Pereira RA, Barros M. Pereira R and Barros M. Factors associated with overweight and central body fat in the city of Rio de Janeiro: results of a two-stage random sampling survey. Public Health. 2001;115(3):236-242. doi:10.1038/sj. ph.1900763

35. Xi B, Liang Y, He T, et al. Secular trends in the prevalence of general and abdominal obesity among Chinese adults, 1993-2009. Obesity Reviews. 2012;13:287-296.

36. Liu X, Chen Y, Boucher NL, Rothberg AE. Boucher NL and Rothberg AE. Prevalence and change of central obesity among US Asian adults: NHANES 2011-2014. BMC Public Health. 2017;17 (1):678. doi:10.1186/s12889-017-4689-6

37. Al-Riyami AA, Afifi MM. Prevalence and correlates of obesity and central obesity among Omani adults. Saudi Med J. 2003;24:641-646.

38. Omar SM, Taha Z, Hassan AA. Al-Wutayd O and Adam I. Prevalence and factors associated with overweight and central obesity among adults in the Eastern Sudan. PLoS One. 2020;15:e0232624.

39. Janakiraman B, Abebe SM. Chala MB and Demissie SF. Epidemiology of General, Central Obesity and Associated CardioMetabolic Risks Among University Employees, Ethiopia: A CrossSectional Study. Diabetes Metab Syndrome Obesity. 2020;13:343. doi:10.2147/DMSO.S235981

40. Zhang P, Wang R, Gao C, et al. Prevalence of central obesity among adults with normal BMI and its association with metabolic diseases in Northeast China. PLoS One. 2016;11(7):e0160402. doi:10.1371/journal.pone. 0160402

41. Hajian-Tilaki K, Heidari B. Prevalence of obesity, central obesity and the associated factors in urban population aged 20-70 years, in the north of Iran: a population-based study and regression approach. Obesity Reviews. 2007;8:3-10. doi:10.1111/j.1467-789X.2006.00235.x

42. Pengpid S, Peltzer K. Prevalence of overweight/obesity and central obesity and its associated factors among a sample of university students in India. Obes Res Clin Pract. 2014;8(6):e558-e70. doi:10.1016/j.orcp.2013.12.003

43. Lfotouh A, Soliman L, Mansour E. Farghaly M and El Dawaiaty A. Central obesity among adults in Egypt: prevalence and associated morbidity. EMHJ-Eastern Mediterranean Health J. 2008;3:124-154.

44. Lear S, James P, Ko GT, Kumanyika S. Ko G and Kumanyika S. Appropriateness of waist circumference and waist-to-hip ratio cutoffs for different ethnic groups. Eur J Clin Nutr. 2010;64(1):42-61. doi:10.1038/ejen.2009.70 
45. Mendez M, Popkin B Globalization, urbanization and nutritional change in the developing world. Globalization of food systems in developing countries: Impact on food security and nutrition. 2004; 5580.

46. Speakman JR. Body size, energy metabolism and lifespan. J Exp Biol. 2005;208(9):1717-1730. doi:10.1242/jeb.01556

47. Atkinson DE Cellular energy metabolism and its regulation. 1977.

48. Tan C-E, Ma S, Wai D, Chew S-K, Tai E-S. Can we apply the National Cholesterol Education Program Adult Treatment Panel definition of the metabolic syndrome to Asians? Diabetes Care. 2004;27 (5):1182-1186. doi:10.2337/diacare.27.5.1182

49. Mirrakhimov AE, Lunegova OS, Kerimkulova AS, Moldokeeva CB. Nabiev MP and Mirrakhimov EM. Cut off values for abdominal obesity as a criterion of metabolic syndrome in an ethnic Kyrgyz population (Central Asian region). Cardiovasc Diabetol. 2012;11:16. doi:10.1186/1475-2840-11-16

50. Ford ES, Maynard LM, Li C. Maynard LM and Li C. Trends in mean waist circumference and abdominal obesity among US adults, 19992012. JAMA. 2014;312(11):1151-1153. doi:10.1001/jama.2014.8362

51. Detection NCEPEPo and Adults ToHBCi. Third Report of the National Cholesterol Education Program (NCEP) Expert Panel on Detection, Evaluation, and Treatment of High Blood Cholesterol in Adults (Adult Treatment Panel III). National Cholesterol Education Program, National Heart, Lung, and Blood; 2002.

52. Tchernof A, Després J-P. Pathophysiology of human visceral obesity: an update. Physiol Rev. 2013.

53. Hu L, Huang X, You C, et al. Prevalence of overweight, obesity, abdominal obesity and obesity-related risk factors in southern China. PLoS One. 2017;12:e183934.

54. Belavý D, Möhlig M, Pfeiffer A. Felsenberg D and Armbrecht G. Preferential deposition of visceral adipose tissue occurs due to physical inactivity. Int J Obes. 2014;38:1478-1480.

55. Rathnayake KM. Roopasingam T and Dibley MJ. High carbohydrate diet and physical inactivity associated with central obesity among premenopausal housewives in Sri Lanka. BMC Res Notes. 2014;7:564.

56. Azadbakht M. Shiva and Azizi. General obesity and central adiposity in a representative sample of Tehranian adults: prevalence and determinants. Int j Vitamin Nutrition Res. 2005;75:297-304.

57. Jackson AS, Stanforth P, Gagnon J, et al. The effect of sex, age and race on estimating percentage body fat from body mass index: the Heritage Family Study. Int J Obes. 2002;26:789-796.
58. Owolabi EO. Ter Goon D and Adeniyi OV. Central obesity and normal-weight central obesity among adults attending healthcare facilities in Buffalo City Metropolitan Municipality, South Africa: a cross-sectional study. J Health Popul Nutr. 2017;36:54.

59. Villanueva B, Arteaga A. Maiz A and Cortes VA. Abdominal obesity is a common finding in normal and overweight subjects of Chile and is associated with increased frequency of cardiometabolic risk factors. PLoS One. 2018;13:e194644.

60. Mokha JS, Srinivasan SR, DasMahapatra P, et al. Utility of waist-toheight ratio in assessing the status of central obesity and related cardiometabolic risk profile among normal weight and overweight/ obese children: the Bogalusa Heart Study. BMC Pediatr. 2010;10:73.

61. WahlqvistBMedSc ML, Wattanapenpaiboon N. Dietary intake and the risk of coronary heart disease among the coconut-consuming Minangkabau in West Sumatra, Indonesia. Asia Pac J Clin Nutr. 2004; 13:377-384.

62. Prior IA, Davidson F. Salmond CE and Czochanska Z. Cholesterol, coconuts, and diet on Polynesian atolls: a natural experiment: the Pukapuka and Tokelau island studies. Am J Clin Nutr. 1981;34:15521561.

63. Assunçao ML, Ferreira HS. dos Santos AF, Cabral CR and Florêncio TM. Effects of dietary coconut oil on the biochemical and anthropometric profiles of women presenting abdominal obesity. Lipids. 2009;44:593-601.

64. Boateng L, Ansong R, Owusu W, Steiner-Asiedu M. Coconut oil and palm oil's role in nutrition, health and national development: A review. Ghana Med J. 2016;50:189-196.

65. Rosqvist F, Iggman D, Kullberg J, et al. Overfeeding polyunsaturated and saturated fat causes distinct effects on liver and visceral fat accumulation in humans. Diabetes. 2014;63:2356-2368.

66. Food and Organization. A. Agriculture, Food and Nutrition for Africa: A Resource Book for Teachers of Agriculture. FAO Rome; 1997.

67. Patterson E, Wall R, Fitzgerald G. Ross R and Stanton C. Health implications of high dietary omega- 6 polyunsaturated fatty acids. $J$ Nutr Metab. 2012;2012.

68. Haczeyni F. Bell-Anderson K and Farrell G. Causes and mechanisms of adipocyte enlargement and adipose expansion. Obesity Reviews. 2018;19:406-420.

Diabetes, Metabolic Syndrome and Obesity: Targets and Therapy

\section{Publish your work in this journal}

Diabetes, Metabolic Syndrome and Obesity: Targets and Therapy is an international, peer-reviewed open-access journal committed to the rapid publication of the latest laboratory and clinical findings in the fields of diabetes, metabolic syndrome and obesity research. Original research, review, case reports, hypothesis formation, expert opinion and commentaries are all considered for publication. The manuscript management system is completely online and includes a very quick and fair peer-review system, which is all easy to use. Visit http://www.dovepress.com/testimonials.php to read real quotes from published authors.

Submit your manuscript here: https://www.dovepress.com/diabetes-metabolic-syndrome-and-obesity-targets-and-therapy-journal 